Janaina Medeiros de Souza ${ }^{1}$

Adriana Dutra Tholl ${ }^{2}$

Fernanda Peixoto Córdova ${ }^{3}$

Ivonete Teresinha Schülter Buss Heidemann ${ }^{2}$

Astrid Eggert Boehs ${ }^{2}$

Rosane Gonçalves Nitschke ${ }^{2}$

'Programa de PósGraduação em Enfermagem (PEN), Universidade

Federal de Santa Catarin (UFSC/Campus Araranguá. Rodovia Governador Jorge Lacerda no 3201, Jardim das Avenidas. 88.900-000 Araranguá SC Brasil. janainamedeirosdesouza@ yahoo.com.br

${ }^{2}$ PEN/UFSC, Departamento de Enfermagem, UFSC.

${ }^{3}$ Hospital de Clínicas de Porto Alegre.

\title{
Aplicabilidade prática do empowerment nas estratégias de promoção da saúde
}

The practical applicability of empowerment in health promotion strategies

Abstract The scope of this study is to identify what empowerment strategies were addressed for the promotion of health in health research, characterizing them from a socio-critical and poststructuralist standpoint. It involved an Integrative Review conducted in May 2011 of the Medline, Lilacs and SciELO databases. The inclusion criteria were complete research articles, case reports or experience reports, published between 2002 and 2011 in Portuguese, Spanish and English. The research criteria included the key words "empowerment" and "health promotion" (DeCS/BIREME). Twenty articles, which presented strategies of individual and/or social empowerment that were characterized by a socio-critical perspective, were selected. It is considered that some activities, mainly those that included thematic discussion groups, represented a mobilization and empowerment strategy. These included theater, culture circles, community therapy, therapeutic learning workshops, home visits, university extension and social action projects. It is considered that all empowerment strategies are inherently health promotion strategies, but not all health promotion strategies effectively result in empowerment.

Key words Empowerment, Health promotion, Health education
Resumo Este estudo tem como objetivo identificar nas pesquisas em saúde quais estratégias de "empowerment" foram abordadas para a promoção da saúde, caracterizando-as na ótica das perspectivas crítico-social e pós-estruturalista. Trata-se de uma Revisão Integrativa realizada em maio de 2011 nas bases de dados Medline, Lilacs e SciELO, com os seguintes critérios de inclusão: artigos completos de pesquisa, relatos de casos ou relatos de experiências publicados no período de 2002 a 2011, em Português, Espanhole Inglês, tendo como critério de busca a palavra-chave "empowerment" e o descritor, "promoção da saúde" (DeCS/Bireme). Foram selecionados 20 artigos, os quais apresentaram estratégias de "empowerment" individual e/ou comunitário e caracterizaram-se em uma perspectiva crítico-social. Acredita-se que algumas atividades, em especial as que envolviam grupos de discussão temática, representaram uma ferramenta mobilizadora e de "empowerment", quais sejam: teatro, círculo de cultura, terapia comunitária, oficinas de escuta terapêutica, visita domiciliar, extensão universitária e projetos de ação social. Compreende-se que toda estratégia de "empowerment" também o é de promoção da saúde, mas nem toda estratégia de promoção da saúde é empoderadora.

Palavras-chave Empowerment, Promoção da saúde, Educação em saúde 


\section{Introdução}

Empowerment é um conceito complexo que toma emprestado noções de distintos campos de conhecimento. É uma ideia que tem origem nos movimentos sociais por direitos civis na década de 1970, no movimento feminista e na ideologia da 'ação social' presentes nas sociedades do primeiro mundo, a partir dos anos 1950. Nos anos 1970, é influenciado pelos movimentos de autoajuda; nos anos 1980, pela psicologia comunitária e nos anos 1990, pelos movimentos que buscam afirmar o direito de cidadania sobre distintas esferas sociais, dentre as quais a prática médica, a educação em saúde e o ambiente físico ${ }^{1,2}$.

O empowerment emerge no cenário das ações em saúde ao ser lançada a Carta de Ottawa, na $1^{\text {a }}$ Conferência Internacional sobre Promoção da Saúde em 1986, quando se define promoção da saúde como o processo pelo qual os indivíduos e a comunidade são capacitados a ter maior controle sobre sua própria saúde, mobilizando recursos pessoais e sociais, que vão além desse setor ${ }^{3,4}$.

Portanto, para efetivar a promoção da saúde dos indivíduos e comunidade foram elencadas, nesse documento, ações e estratégias de construção de políticas públicas saudáveis; criação de ambientes sustentáveis; reforço da ação comunitária; desenvolvimento de habilidades pessoais e reorientação dos serviços de saúde ${ }^{3}$.

Empowerment é compreendido como o processo de saúde comprometido com a transformação da realidade e a produção de saúde e de sujeitos saudáveis, sendo a efetiva e concreta participação social estabelecida como objetivo essencial da promoção de saúde ${ }^{1,3}$.

Outro conceito de empowerment que merece destaque o caracteriza como processo social que favorece a participação das pessoas, das organizações e da comunidade ampliando o controle destes na ação política, com melhores condições de vida da comunidade e justiça social desse grupo de pessoas ${ }^{1,5}$.

Na concepção de Paulo Freire, o empoderamento (empowerment) pode ser entendido como um processo que emerge das interações sociais, nas quais os seres humanos problematizam a realidade, e a medida que vão desvelando a realidade se empoderam para transformar as relações sociais de dominação ${ }^{6}$.

Pode-se considerar o empowerment como um eixo que une consciência e liberdade. Ele resulta de uma práxis reflexiva e inserção crítica das pessoas, estimulado pelas perguntas que as colocam em ação $0^{7}$.
O termo empowement tem sido foco de interesse de diversos estudos, apontados por $\mathrm{Cu}-$ nha ${ }^{8}$, por tratar da liberdade de escolha, direito à informação e esclarecimento da saúde pelas pessoas. A esperança em atingir um grau de empowerment que mobilize as pessoas para a tomada de consciência de sua situação atual, para que, motivadas, possam caminhar rumo à consolidação da materialização das políticas de saúde em prol de seu bem-estar por uma vida digna, constitui uma responsabilidade social.

Essa dificuldade de definição reflete-se quando tal conceito vem sendo traduzido com distintos significados para o português e o espanhol. Carvalho ${ }^{1}$ ressalta que este termo é sinônimo de "apoderamento", o que significa dar posse, ter domínio de, apossar-se, assenhorear-se, dominar, conquistar e tomar posse. Também tem conotação de "emancipación", que significa emancipar, tornar livre e independente. Portanto, pela inexistência do termo "empoderamento" na Língua Portuguesa e a divergência do sentido de "apoderamento", opta-se por utilizar o termo empowerment, termo derivado da língua inglesa.

Retomando a complexidade do conceito empowerment, Carvalho e Gastaldo ${ }^{9}$ avançam na discussão abordando esse conceito e o poder sob as duas perspectivas: crítico-social e pós-estruturalista.

Para os crítico-sociais e estruturalistas, o modo de viver existe a partir da estrutura social em que o sujeito está inserido, de forma que ele não é visto como o elemento principal dessa produção, mas um dos elementos periféricos ${ }^{10-11}$. Nesta forma de pensamento, os fatos do cotidiano têm suas formas de pensar e fazer, influenciadas por relações de poder que precisam ser problematizadas e compreendidas como um produto de relações sociais e históricas que tendem a naturalizar e reproduzir desigualdades ${ }^{1,9}$.

Na perspectiva do referencial crítico-social, o empowerment possui dois sentidos: psicológico (ou individual) e social (ou comunitário). $\mathrm{O}$ empowerment psicológico ou individual possibilita que os indivíduos tenham um sentimento de maior controle sobre a própria vida, capaz de influenciar e adaptar-se ao seu meio e desenvolver mecanismos de autoajuda e de solidariedade ${ }^{1,9}$.

$\mathrm{O}$ empowerment social ou comunitário busca destacar a ideia da saúde como um processo e uma resultante de lutas de coletivos sociais por seus direitos. Ele não nega o psicológico, mas procura destacar a importância de enfrentar as raízes e as causas da iniquidade social. Entretanto, para que o empowerment social se efetive é necessário 
ter ciência de que a macroestrutura condiciona e determina o cotidiano dos indivíduos, estes, por sua vez, influenciam e significam o plano macrossocial, em um movimento circular e interdependente ${ }^{9}$. Estas colocações têm estreita relação com as ideias de libertação trabalhadas por Paulo Freire, nas quais os indivíduos e a coletividade se libertam por meio da educação $0^{12,13}$.

A perspectiva pós-estruturalista surge a partir das discussões acerca das relações de poder e subjetividade e, mais especificamente, sobre a constituição de uma das formas de poder estudadas por Michael Foucault, o poder disciplinar, que age na docilização dos corpos. Essa perspectiva teórica considera que realidades e verdades constituídas são temporais, e que são produzidas em tensões entre discursos dominantes e emergentes, na tentativa de manter ou modificar determinadas práticas sociais estabelecidas. Para o pós-estruturalismo, as pessoas são constituídas dos mesmos discursos que compõem o seu "exterior", o que torna difícil distinguir interioridade de exterioridade, questionando a noção de sujeito autônomo, com um self independente e com possibilidade de livre escolha ${ }^{9}$. Nesta perspectiva, o poder passa a ser compreendido como uma prática social histórica e não como uma "coisa", um objeto natural que alguns possuem. Todos exercem poder, governam e são governados por discursos dominantes compartilhados, produzindo, inclusive, desejo e necessidades que as pessoas assumem, "naturalmente", como suas?.

A partir de reflexões da práxis acadêmica e profissional acerca de estratégias de promoção da saúde, buscou-se caracterizar os múltiplos conceitos e interpretações de empowerment e de relacioná-los com as políticas públicas e as ações específicas de saúde. Acredita-se que as estratégias de empowerment, na perspectiva de desenvolvimento da autonomia e emancipação dos sujeitos, exercem impacto sobre a promoção da saúde e a redução da iniquidade ${ }^{14}$.

Neste sentido, constatou-se que o empowerment vem sendo pesquisado de forma ampla no campo teórico, porém, ao mesmo tempo, os profissionais da saúde têm encontrado dificuldades na sua aplicabilidade prática, ou seja, de realizar estratégias que atinjam de fato o "empoderamento" dos usuários.

Para tanto, o objetivo deste estudo é identificar, nas publicações em saúde, quais estratégias de empowerment foram abordadas para a promoção da saúde, caracterizando-as na ótica das perspectivas crítico-social e pós-estruturalista.

\section{Metodologia}

Trata-se de revisão integrativa ${ }^{15,16}$, considerada uma técnica de pesquisa que inclui análise de pesquisas relevantes possibilitando a síntese do estado de conhecimento de um determinado assunto, além de apontar lacunas do conhecimento que precisam ser preenchidas com a realização de novos estudos. Este método de pesquisa permite a síntese de múltiplos estudos publicados e possibilita conclusões gerais a respeito de uma área particular de investigação.

Embora os métodos para a condução de revisões integrativas variem, existem padrões a serem seguidos. $\mathrm{Na}$ operacionalização desta revisão, utilizou-se as seguintes etapas: seleção das questões temáticas; estabelecimento dos critérios para a seleção da amostra; representação das características da pesquisa original; análise dos dados; interpretação dos resultados; apresentação da revisão ${ }^{15}$.

O estudo constituiu-se dos artigos indexados nas bases de dados Medline (Literatura Internacional em Ciências da Saúde/Medical Literature Analysis and Retrieval System On-line), Lilacs (Literatura Latino-Americana e do Caribe em Ciências da Saúde) e SciELO (Scientific Electronic Library On-line), sobre as estratégias do empowerment para a promoção da saúde.

Para estabelecer a amostra de estudo foram criados critérios de inclusão, a saber: serem artigos completos de pesquisa, de relato de caso ou de relatos de experiências, publicados no período de 2002 a 2011 nos idiomas Português, Espanhol e Inglês. Utilizou-se a busca pelos artigos através da palavra-chave "empowerment" e pelo descritor, em Ciências da Saúde do Centro Latino-americano e do Caribe de Informação em Ciências da Saúde (DeCS/Bireme), "promoção da saúde".

Optou-se pelo uso da palavra empowerment, ao invés do descritor "Poder" indexado no DeCS, por este não atender ao objeto de estudo, já que é definido pelo DeCS como ter grande influência ou controle sobre os outros em uma variedade de contextos. Neste estudo, entende-se por empowerment, não uma relação de poder sobre o outro, mas uma relação de poder com o outro, em uma relação emancipatória.

Para direcionar a revisão integrativa, fez-se a seguinte questão norteadora: Quais estratégias de empowerment foram abordadas para a promoção da saúde, em publicações em saúde, desenvolvidas no período de 2002 a 2011 ? 
A busca nas bases de dados aconteceu em maio/2011 e resultou em 71 artigos completos, sendo que 11 eram repetidos em mais de uma base de dados, totalizando 60 artigos. Após leitura dos artigos completos, foram selecionados 20 com base nos critérios de inclusão estabelecidos e na questão norteadora da pesquisa.

A análise dos dados foi realizada em duas etapas. Na primeira, foram identificados os dados de localização do artigo (título do artigo, autores, título do periódico, volume, número, ano, objetivo, desenho metodológico, estratégias de empowerment e resultados, classificação da estratégia, de acordo com as perspectivas críticosocial e pós-estruturalista), utilizando-se um instrumento elaborado especificamente para este estudo. Na segunda etapa, ocorreu a análise das informações contidas nos artigos, objetivando identificar quais estratégias de empowerment foram implementadas para a promoção da saúde, analisando-as sob a ótica das perspectivas crítico-social e pós-estruturalista.

Realizou-se a classificação dos artigos, a partir de suas características predominantes, ainda que, alguns estudos não trouxessem descritos, claramente, todas as informações do interesse desta pesquisa. Seguindo-se a esta etapa, realizou-se a inter-relação dos dados com as literaturas pertinentes, para a apresentação da revisão integrativa. Para melhor apresentação dos mesmos, foram utilizados quadros e análises, realizados através de frequências absolutas simples.

Os artigos foram identificados pela letra " $\mathrm{A}$ ", seguida de números arábicos, decrescentemente, por ano de publicação. Os números entre parênteses indicam suas respectivas referências (trazidas ao final do artigo), na ordem em que foram apresentadas nos Quadros e seguindo a ordem de citação de autoria ao longo do texto.

\section{Resultados e discussão}

No Quadro 1 são apresentadas as informações relativas aos estudos quanto à sua identificação, objetivos e desenho metodológico adotado.

Observou-se que o periódico que obteve o maior número de publicações concernente ao empowerment foi Ciência \& Saúde Coletiva $(\mathrm{n}=$ 3), seguido do Biomedical Central Public Health (BMC), Cadernos de Saúde Pública, Interface: Comunicação, Saúde, Educação e Texto Contexto em Enfermagem, com 2 artigos em cada. Quanto ao período de análise, em 2010 constatou-se um crescente aumento de publicações $(\mathrm{n}=8)$.
Sugere-se que este fato possa ter relação com a crescente preocupação de avaliação das políticas de saúde, bem como a efetividade das estratégias de promoção desenvolvidas no âmbito dos sistemas de saúde.

Ao analisar os delineamentos de pesquisa mais frequentes na amostra estudada, identificou-se que 12 utilizaram a abordagem metodológica qualitativa, 2 desenvolveram estudos com métodos quantitativos, 2 realizaram estudos quali-quantitativos, 3 foram relatos de experiência e 1 relato de caso. Tendo em vista a multiplicidade de fatores envolvidos na conceituação e definição teórica de empowerment e a abordagem que as práticas voltadas à promoção da saúde requerem, justifica a adoção de estudos predominantemente qualitativos.

Considerando-se o desenho metodológico dos estudos, no que se refere à tipologia dos mesmos, a maioria deles, tinha, como objetivos de pesquisa, descrever propostas de avaliação e de intervenção por meio de práticas educativas em saúde, de forma que se caracterizaram como descritivos ou exploratórios $(\mathrm{n}=10)$. Em seguida, observou-se maior frequência de realização de pesquisas do tipo pesquisa-ação $(n=3)$, pesquisa participante $(\mathrm{n}=2)$ e outras tipologias de estudo $(\mathrm{n}=5)$.

O quadro 2 apresenta a relação de estratégias de empowerment implementadas nos estudos analisados e a sua caracterização quanto à definição teórica.

Analisando os estudos quanto aos objetivos e às estratégias de empowerment implementadas (Quadro 2), evidencia-se uma tendência teórica voltada à perspectiva crítico-social. Em sua maioria, os estudos abordam estratégias voltadas a um dos eixos da Carta de Ottawa, em especial: reforço da ação comunitária, desenvolvimento de habilidades pessoais, criação de ambientes sustentáveis e construção de políticas públicas saudáveis. Assim, entende-se que as estratégias implementadas e apresentadas nos estudos direcionam-se aos princípios da Promoção da Saúde ${ }^{2,9,17}$.

No entanto, pode-se inferir formas relacionais de poder dentro da perspectiva pós-estruturalista. Pois, segundo Foucault ${ }^{18}$, em todos os tipos de relações humanas, em diferentes esferas da vida, o poder está sempre presente. É a relação em que cada um procura dirigir a conduta do outro. São, portanto, "relações que se podem encontrar em diferentes níveis, sob diferentes formas; essas relações de poder são móveis, ou seja, podem se modificar, não são dadas de uma vez por todas". 
Quadro 1. Caracterização dos estudos selecionados quanto ao título do periódico, objetivos e desenho metodológico, em ordem cronológica decrescente de publicação, acerca de estratégias de empowerment na promoção da saúde (2002-2011).

\begin{tabular}{|c|c|c|c|}
\hline Sigla & Periódico & Objetivos & $\begin{array}{l}\text { Desenho } \\
\text { Metodológico }\end{array}$ \\
\hline A 1 & $\begin{array}{l}\text { Ciência \& Saúde } \\
\text { Coletiva }(2011)^{19}\end{array}$ & $\begin{array}{l}\text { Descrever o movimento de promoção à saúde e } \\
\text { prevenção da Aids entre prostitutas do Rio de } \\
\text { Janeiro e Niterói. }\end{array}$ & Descritiva \\
\hline A 2 & $\begin{array}{l}\text { Acta Paulista de } \\
\text { Enfermagem }(2010)^{20}\end{array}$ & $\begin{array}{l}\text { Descrever a experiência na elaboração de um } \\
\text { espetáculo teatral com adolescentes para estimular a } \\
\text { reflexão sobre a realidade e contribuir para a } \\
\text { redução da violência. }\end{array}$ & $\begin{array}{l}\text { Exploratório } \\
\text { Descritivo }\end{array}$ \\
\hline A3 & $\begin{array}{l}\text { Biomedical Central } \\
(\text { BMC) Public Health } \\
(2010)^{21}\end{array}$ & $\begin{array}{l}\text { Explorar a aplicação da política de Halsotorg (HS) a } \\
\text { nível local e analisar as atividades do HS. }\end{array}$ & $\begin{array}{l}\text { Descritivo } \\
\text { Levantamento }\end{array}$ \\
\hline A 4 & $\begin{array}{l}\text { Interface (Botucatu) } \\
(2010)^{22}\end{array}$ & $\begin{array}{l}\text { Identificar as expectativas e percepções das meninas } \\
\text { participantes de atividades de extensão (lúdicas e } \\
\text { educativas): teatro, fantoches, histórias de vida, } \\
\text { maquetes, jogos educativos, passeios. }\end{array}$ & $\begin{array}{l}\text { Pesquisa } \\
\text { Participante }\end{array}$ \\
\hline A 5 & $\begin{array}{l}\text { Interface: (Botucatu) } \\
(2010)^{23}\end{array}$ & $\begin{array}{l}\text { Analisar a capacitação dos líderes da Pastoral da } \\
\text { Criança da Igreja Católica e identificar } \\
\text { potencialidades e fragilidades para a promoção da } \\
\text { saúde bucal. }\end{array}$ & $\begin{array}{l}\text { Pesquisa } \\
\text { Participante }\end{array}$ \\
\hline A6 & $\begin{array}{l}\text { Journal for Specialists } \\
\text { in Pediatric Nursing } \\
(2010)^{24}\end{array}$ & $\begin{array}{l}\text { Descrever uma intervenção de visita domiciliar para } \\
\text { jovens fugitivas agredidas sexualmente (10-14 anos). }\end{array}$ & $\begin{array}{l}\text { Exploratório } \\
\text { Descritivo }\end{array}$ \\
\hline A7 & $\begin{array}{l}\text { Revista Brasileira de } \\
\text { Enfermagem }(2010)^{25}\end{array}$ & $\begin{array}{l}\text { Sistematizar, com as participantes dos Círculos de } \\
\text { Cultura, (re)construção das ações de Educação em } \\
\text { Saúde que articulem as competências necessárias } \\
\text { aos(às) enfermeiros(as) de PSF. }\end{array}$ & Pesquisa-ação \\
\hline A 8 & $\begin{array}{l}\text { Saúde e Sociedade } \\
(2010)^{26}\end{array}$ & $\begin{array}{l}\text { Avaliar os processos de participação e empowerment } \\
\text { da comunidade, a partir de ações desencadeadas } \\
\text { pelo Programa Bairro Ecológico (PBE). }\end{array}$ & Exploratório \\
\hline A9 & $\begin{array}{l}\text { Texto e Contexto em } \\
\text { Enfermagem }(2010)^{27}\end{array}$ & $\begin{array}{l}\text { Conhecer as contribuições da Terapia Comunitária } \\
\text { para a vida dos idosos. }\end{array}$ & Exploratório \\
\hline A 10 & $\begin{array}{l}\text { Cadernos de Saúde } \\
\text { Pública }(2009)^{28}\end{array}$ & $\begin{array}{l}\text { Identificar o conhecimento da população da Grande } \\
\text { Buenos Aires sobre a dengue e seu mecanismo de } \\
\text { transmissão e a estratégias para promover a } \\
\text { coparticipação comunitária nos problemas } \\
\text { ambientais e de saúde. }\end{array}$ & Descritivo \\
\hline A 11 & $\begin{array}{l}\text { Journal of Health, } \\
\text { Population and } \\
\text { Nutrition }(2009)^{29}\end{array}$ & $\begin{array}{l}\text { Analisar os motivos/fatores primários de exclusão e } \\
\text { como o projeto "Stipend Project" (de bolsa) pode } \\
\text { reduzir estes fatores em garotas de Bangladesh. }\end{array}$ & Pesquisa Histórica \\
\hline
\end{tabular}




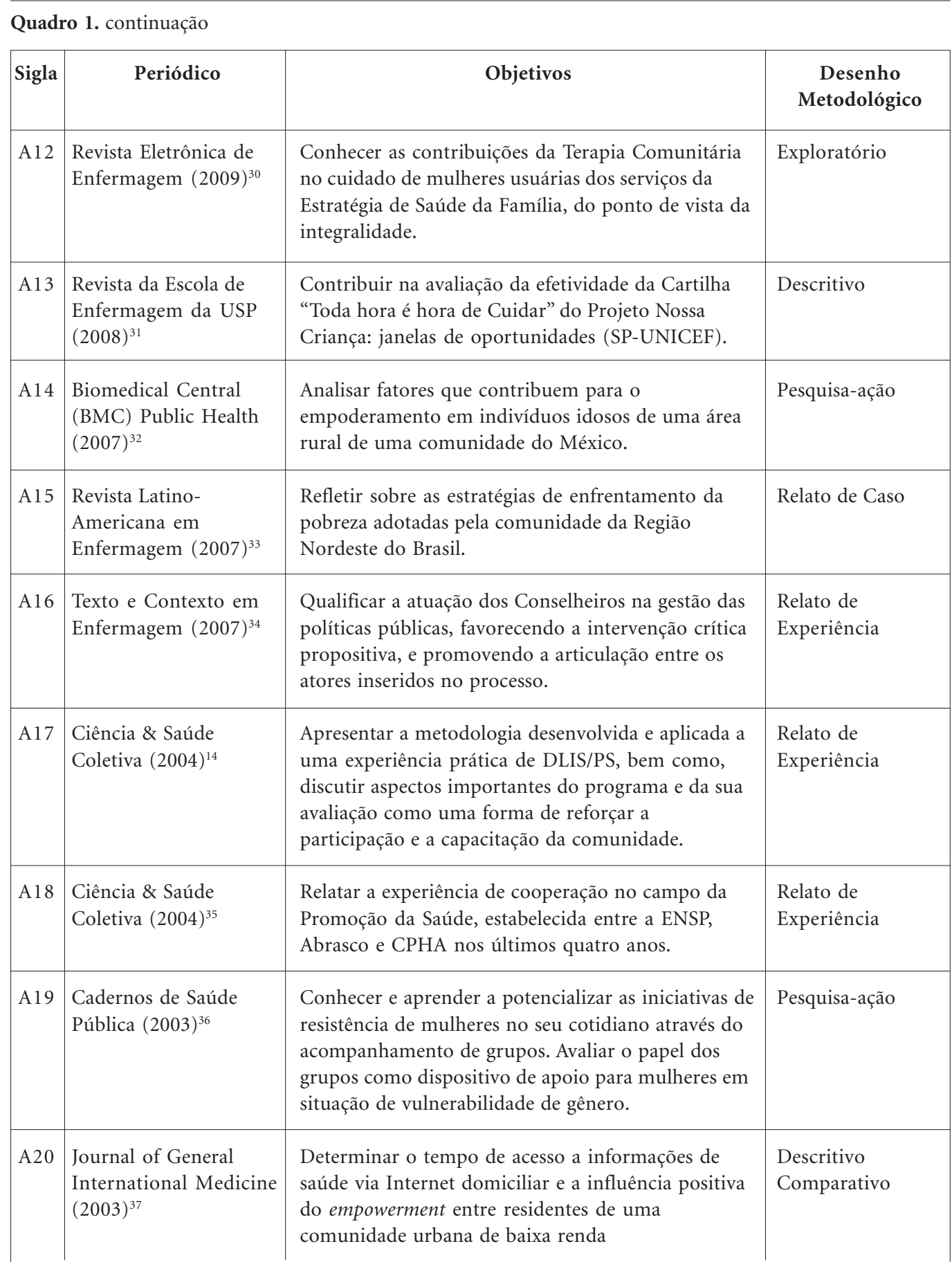

Fonte: Bases de dados da BVS: LILACS, MEDLINE e SciELO, 2011.

As estratégias de terapia comunitária e oficina de escuta terapêutica abordadas nos estudos A9, A12 e A19 foram descritas pelos autores como atividades voltadas às políticas de saúde mental do idoso e da mulher. Dentro de uma perspectiva crítico-social, os autores argumentam que promoveram engajamento social destes grupos, desenvolvimento de autonomia e capacidade de resiliência, especialmente direcionadas ao empowerment individual destes indivíduos e à construção de sua subjetividade.

Analisando-se numa perspectiva pós-estruturalista, velhas tecnologias de poder, como o interrogatório e o uso de drogas, geram formas 
Quadro 2. Relação de Estratégias de Empowerment implementadas nos estudos analisados e a sua caracterização quanto à definição teórica.

\begin{tabular}{|c|c|c|c|}
\hline \multirow{2}{*}{$\begin{array}{l}\text { Sigla } \\
\text { Artigo }\end{array}$} & \multirow[b]{2}{*}{ Estratégia de Empowerment } & \multicolumn{2}{|c|}{ Empowerment } \\
\hline & & Individual & Comunitário \\
\hline A 1 & Passeata promovida por uma ONG em uma área de prostituição & Sim & $\operatorname{Sim}$ \\
\hline A 2 & Teatro com grupos de adolescentes & - & $\operatorname{Sim}$ \\
\hline A3 & $\begin{array}{l}\text { Projeto Social denominado "Halsotorg", com atividades de cuidado e } \\
\text { educação em saúde para a população }\end{array}$ & - & Sim \\
\hline A 4 & $\begin{array}{l}\text { Programa Univali Mulher, projeto de extensão com atividades lúdicas } \\
\text { para promover a educação sexual }\end{array}$ & Sim & - \\
\hline A 5 & $\begin{array}{l}\text { Grupo de Discussão do material (Guia do Líder) com os líderes da } \\
\text { Pastoral da Criança }\end{array}$ & Sim & Sim \\
\hline A6 & $\begin{array}{l}\text { Programa de Ação Social de intervenção com adolescentes exploradas } \\
\text { sexualmente, por meio de visitas domiciliares }\end{array}$ & Sim & - \\
\hline A7 & $\begin{array}{l}\text { Círculo de Cultura com Enfermeiros do Programa de Saúde da } \\
\text { Família (PSF) }\end{array}$ & - & Sim \\
\hline A 8 & Programa Bairro Ecológico para proteção de áreas de mananciais & - & Sim \\
\hline A9 & Terapia Comunitária com idosos usuários do PSF & Sim & Sim \\
\hline A 10 & $\begin{array}{l}\text { Diagnóstico Sanitário, por meio de análise de fotos do ambiente da } \\
\text { comunidade local, pelo grupo de Agentes Comunitários de saúde } \\
\text { (ACS)Atividades Educativas nas escolas da comunidade }\end{array}$ & - & Sim \\
\hline A 11 & Projeto Social (Bolsa Escola) para meninas de escola secundária & - & Sim \\
\hline A 12 & Terapia Comunitária com mulheres usuárias dos serviços da ESF & Sim & - \\
\hline A 13 & $\begin{array}{l}\text { Atividade de Educação em Saúde por meio de cartilhas distribuídas } \\
\text { pelos ACS em visitas domiciliares }\end{array}$ & Sim & - \\
\hline A 14 & Workshop, programa de capacitação para idosos de zona rural & Sim & - \\
\hline A 15 & Viabilização de microcrédito com criação do Banco Palmas & - & $\operatorname{Sim}$ \\
\hline A 16 & Curso de Capacitação para Conselheiros municipais & - & Sim \\
\hline A 17 & $\begin{array}{l}\text { Programa Desenvolvimento Local Integrado Sustentável com foco } \\
\text { na promoção da saúde }\end{array}$ & - & Sim \\
\hline A 18 & $\begin{array}{l}\text { Projeto de Cooperação entre Países para avaliação e diagnóstico } \\
\text { participativo e práticas reflexivas sobre processos sustentáveis de } \\
\text { melhoria dos ambientes físicos e sociais com impacto na saúde }\end{array}$ & - & Sim \\
\hline A 19 & $\begin{array}{l}\text { Oficinas de escuta terapêutica, seguidas de visitas domiciliar, com } \\
\text { mulheres em situação de vulnerabilidade }\end{array}$ & Sim & - \\
\hline A 20 & $\begin{array}{l}\text { Provimento do acesso à Internet no domicílio para residentes de uma } \\
\text { comunidade urbana de baixa renda }\end{array}$ & - & Sim \\
\hline
\end{tabular}

Fonte: Bases de dados da BVS: LILACS, MEDLINE e SciELO, 2011. 
de docilização (senão pelo encerramento físico, mas pelo isolamento químico) e ainda se perpetuam nos centros psiquiátricos de referência no Brasil, conhecidos como CAPS ${ }^{38}$. Ações e estratégias como melhoria da estrutura, medicação adequada e programas de inserção comunitária, como os mencionados nos artigos, podem auxiliar na discussão de ação psiquiátrica em novos espaços de atendimento ${ }^{38}$.

As estratégias mencionadas nos estudos A1, A2, A4, A10 e A14, voltadas a propostas de educação em saúde, tais como: teatro, atividades lúdicas e educativas e workshops trabalhavam tanto o empowerment individual quanto o comunitário (coletivo), voltados à perspectiva crítico-social, e possuíam relação com ações para a promoção da saúde, definidas na Carta de Otawa ${ }^{3}$, quais sejam: o desenvolvimento de habilidades pessoais, o reforço à ação comunitária e a criacão de ambientes saudáveis. Além disso, as estratégias apontadas pelos resultados dos estudos realizados em âmbito nacional refletem iniciativas direcionadas às diretrizes do Plano Nacional de Promoção da Saúde, por meio do fortalecimento da participação social ${ }^{39}$.

Em relação às estratégias de empowermet, Vasconcelos ${ }^{40}$ refere que existem diversas abordagens, com diferentes perspectivas, dependendo do objetivo e do contexto das relações interpessoais, institucionais e sociais nas quais se inserem. Para este autor existem também as abordagens e as estratégias diretamente voltadas para o trabalho profissional, como na área social, em saúde e em saúde mental, nas quais o profissional busca ter um papel ativo de estimular o empowerment de seus usuários e clientes, de forma individual, em grupos, no trabalho comunitário e institucional. Elenca, ainda, diversas estratégias de empowerment para superar processos de exclusão, opressão e discriminação tais como: recuperação de uma doença ou deficiência, cuidado de si, ajuda mútua, suporte mútuo e participação no sistema de saúde.

Ainda relacionado a um dos eixos da promoção da saúde, descrito na Carta de Otawa, a criação de ambientes favoráveis e sustentáveis, alguns estudos analisados (A8, A10, A17, A18) desenvolveram ações de envolvimento das comunidades no diagnóstico ambiental e em práticas reflexivas de conservação e processos sustentáveis para os ambientes que tivessem impacto na saúde. Em uma perspectiva crítico-social, este eixo de promoção da saúde envolve luta constante, uma vez que o prejuízo ambiental e humano pode ocasionar desequilíbrios no ecossistema e que os êxitos neste sentido dependem de elaboração de políticas públicas saudáveis, por meio de estratégias municipais voltadas à sustentabilidade e reorientação dos serviços de saúde ${ }^{41}$.

No estudo A20, os autores procuraram retratar a oferta de acesso à Internet nos domicílios como uma estratégia de empowerment, no sentido de disponibilizar acesso às informações e promover inclusão social através da inclusão digital. A internet vem mudando a dinâmica de comunicação em todo o mundo, possibilitando aos cidadãos em diferentes esferas, como governo, escolas, empresas e universidade, a inclusão digital como forma de combate da exclusão social e econômica ${ }^{42}$.

Para os estudos que envolveram diretamente a coparticipação dos sujeitos nas decisões (A1, $\mathrm{A} 2, \mathrm{~A} 7, \mathrm{~A} 8, \mathrm{A10}, \mathrm{A17}, \mathrm{A19}$ ), destaca-se que a forma como estes fazem suas escolhas tem estreita relação com a capacidade de participação, mas também com a distribuição do poder nesses espaços $^{43}$. Também, neste sentido, é destacado que a educação em saúde pode ser considerada como conteúdo naturalmente integrante em qualquer nível da atenção. Programas ou atividades educativas podem fazer parte de qualquer ação de saúde, tanto de promoção, prevenção, como de cura e reabilitação ${ }^{44}$. Ainda, um dos aspetos fundamentais do empowerment diz respeito às possibilidades de que a ação local fomente a formação de alianças políticas capazes de ampliar o debate da opressão no sentido de contextualizála e favorecer a sua compreensão como fenômeno histórico, estrutural e político ${ }^{45}$.

$\mathrm{Na}$ perspectiva critico-social, para que o indivíduo e seus grupos sociais construam um processo efetivo de promoção à saúde, é preciso que estes atinjam um grau elevado de empowerment psicológico ou individual, associado a uma participação ativa na ação política e possibilidade de conquista de recursos materiais ou de poder por parte destes indivíduos ou coletivos (empowerment social) ${ }^{1}$. Na perspectiva pós-estruturalista, o corpo passa a ser instrumento do exercício do poder, como afirma Foucault ${ }^{18}$ : o controle da sociedade sobre os indivíduos não se opera simplesmente pela consciência ou pela ideologia, mas começa no corpo, com o corpo. Foi no biológico, no somático, no corporal que, antes de tudo, investiu a sociedade capitalista. O corpo é uma realidade biopolítica.

Os estudos A1 e A5, em suas discussões, mencionam não ter concluído ou atingido resultados satisfatórios para o empowerment dos sujeitos. $\mathrm{O}$ estudo $\mathrm{A} 5$, por chegar à conclusão de que a 
abordagem educativa adotada foi predominantemente técnica e informacional que não favoreceu o processo de empowerment dos sujeitos. $\mathrm{O}$ estudo A1, objetivando criar um movimento comunitário de prostitutas, com a realização de uma passeata para campanha do uso de preservativo pelos seus clientes, destaca que não obteve os resultados esperados, uma vez, que as próprias prostitutas não aderiram ao movimento.

Numa perspectiva crítico-social, o empowerment social é considerado um processo que conduz à legitimação e dá voz a grupos marginalizados, ao mesmo tempo que remove barreiras que limitam a produção de uma vida saudável para distintos grupos sociais ${ }^{1}$. No estudo realizado com as prostitutas, o mesmo não ocorreu. As autoras justificam que tal situação possa ter acontecido, uma vez que os mecanismos de defesa contra o estigma preveniam o sofrimento das prostitutas, mas impediam, ao mesmo tempo, o surgimento de uma "narrativa de identidade de prostituta", boicotando a organização do grupo e a emergência de um movimento comunitário. Visto numa perspectiva pós-estruturalista, a questão da diferença, da subjetividade e da singularidade das experiências, são construídas pelos discursos, em um campo que é sempre dialógico e intersubjetivo. Ainda, de acordo com os escritos tardios de Foucault, esta atitude das prostitutas pode ser vista como uma forma de resistência ao poder ${ }^{9,18}$.

$\mathrm{O}$ fato do empowerment social reconhecer o caráter relacional do poder e da iniquidade contribui para a repolitização do debate sanitário, mudanças do status quo; no entanto, pode ser insuficiente e ambíguo para a concretização de ações de produção e promoção da saúde?. Tais ações exigem práticas educativas que promovam a participação dos indivíduos na identificação e na análise crítica de seus problemas, visando a elaboração de estratégias de ação que busquem a transformação na realidade ${ }^{1}$.

O estudo A13 também não atingiu níveis de empowerment, uma vez que realizou simplesmente a entrega de uma Cartilha aos pais com informações sobre como cuidar de crianças, caracterizando-se como uma atividade informacional e de prevenção. As práticas de educação em saúde preventiva ignoram que comportamentos são sempre interativos, o que significa que modos de vida são produtos de uma ação recíproca de fatores socioculturais e individuais $s^{4}$. Além disso, a educação como um simples instrumento de transmissão de informações, no sentido de uma "educação bancária" ${ }^{13}$, caracteriza um modo convencio- nal de fazê-la e não atinge a promoção da saúde ${ }^{36}$. Importa salientar que se valorize propostas pedagógicas empoderadoras, através da criação de espaços dialógicos e de cogestão em que se privilegia o exercício do poder com o outro e se desenvolve a capacidade de escuta com o outro ${ }^{9,13}$.

Por fim, o projeto sobre a cooperação entre Brasil e Canadá, descrito no estudo A18, realizou um diagnóstico participativo, em que foi aprofundada a percepção dos vários segmentos da realidade, tais como: saúde, educação, trabalho e renda, ambiente, política institucional, infraestrutura. Diante disso, a partir da Carta de Otawa ${ }^{3}$ pode-se inferir que ações de empowerment foram iniciadas, entretanto, a consolidação das mesmas só se dará na mobilização de parceiros e recursos para colocar em prática o que se propôs.

A partir dos confrontos teóricos das autoras deste estudo na análise dos artigos e identificação das estratégias de empowerment, observa-se uma inclinação para a perspectiva crítico-social, possivelmente relacionada à forma mais palpável deste referencial de dar aplicabilidade prática, que confere a visão de que há um poder maior contra o qual há necessidade de uma reação contrária, sendo que esta pode ser prática, diferentemente da perspectiva pós-estruturalista, em que as relações de poder ocorrem de uma forma subliminar, envolvendo os indivíduos e a sua subjetividade.

Neste sentido, supõe-se que a limitação de se articular estratégias de empowerment, que atinjam os pressupostos da perspectiva pós-estruturalista, reside no fato de que, sendo o poder constituído por uma complexa trama de micro e macropoderes, envolveria a interpretação dos processos de subjetividade de cada sujeito e políticas e estratégias intrassetoriais e intersetoriais, não somente ligadas ao setor saúde. Considerando as dificuldades, no Brasil, em termos territoriais, socioeconômicos e culturais de implementar tais políticas e estratégias, os estudos que se direcionam para o empowement na perspectiva criticosocial e com fortes raízes nos trabalhos de Paulo Freire, têm contribuído com a (re)politização dos debates e das práticas em saúde.

Contudo, analisando os resultados apontados pelos estudos a partir das estratégias ditas empoderadoras, podemos considerar que muitas das mesmas revelam, subliminarmente, maneiras de realizar a vigilância dos indivíduos e de exercício de poder por parte dos gestores e profissionais de saúde. De um ponto de vista técnico, a saúde pode ser considerada como um tipo específico de poder ou autoridade, chamado de Poder de Proporcionar Saúde; poder este de que 
é investido um conjunto de profissionais ou especialistas para: conceituar saúde; prescrever saúde (comportamentos saudáveis); produzir tecnologia e ações, que, por sua vez, produzirão um "efeito" de saúde em indivíduos e populações; e, finalmente, para atestar que uma dada pessoa ou comunidade é, ou está, saudável ou doente.

$\mathrm{Na}$ visão da perspectiva pós-estruturalista, as dimensões criativas e instituintes do poder podem gerar, simultaneamente, formas de docilização e de resistência ou criação, em uma formulação paradoxal ${ }^{46}$. Portanto, a vida constitui o alvo das lutas biopolíticas, mesmo sob a forma de lutas pelo direito à vida, à saúde, ao corpo, à higiene, ao bem-estar e à satisfação das necessidades. A biopolítica precisa da resistência ao dispositivo biopolítico para poder se desenvolver ${ }^{47}$. Muitas das estratégias de saúde propostas para a população podem ter um poder disciplinador, através da anátomo-política e do biopoder, ao transformar-se em mecanismo de regulação e de controle do social de certos grupos ${ }^{9}$. Entretanto, analisando-se a visão positiva de poder postulada por Foucault ${ }^{18}$, em uma perspectiva pós-estruturalista, entende-se que as relações de poder desenvolvidas entre os sujeitos em estratégias de promoção da saúde podem ter um valor transformador e produtivo, de reconstruir novos discursos e novas subjetividades.

Para o desenvolvimento do empowerment psicológico ou individual, as ações e as estratégias sociais e de saúde devem estar direcionadas a um processo de construção de autoestima, autoconfiança e independência nos indivíduos, reforçando seu poder de atuação coletiva ${ }^{1}$. E para o desenvolvimento do empowerment social ou comunitário, faz-se necessário propor abordagens educativas que valorizam a criação de espaços públicos (rodas e grupos de discussão), colegiados, com o objetivo de identificar e analisar criticamente seus problemas, possibilitando estratégias conjuntas de transformação da realidade social, reorganização das práticas assistenciais, repensando os programas de prevenção marcados pelo modelo biomédico e superação da desigualdade de poder que predomina na relação entre os profissionais e usuários.

Finalizando, trata-se então de superar no campo das discussões sobre o processo saúde/doença, todos os tipos de propostas "educativas", caminhando em direção a estratégias de empowerment; levando ao estabelecimento de relações dialógicas e de controle entre os indivíduos, considerados individual ou coletivamente, e as instâncias mediadoras, sejam estas profissionais de saúde, poder público, tecnologias, serviços, produtos ou combinações desses elementos ${ }^{42}$.

\section{Considerações finais}

Ao finalizar o presente estudo, retoma-se o objetivo que é identificar as estratégias de empowerment abordadas para a promoção da saúde, caracterizando-as nas perspectivas crítico-social e pós-estruturalista.

Pela caracterização das publicações analisadas, considera-se que os artigos científicos estudados têm um caráter crítico-social. Embora tenha crescido numericamente, nos últimos anos, o interesse por pesquisas objetivando a implementação e a avaliação de estratégias de empowerment para a promoção da saúde, possivelmente pela constante preocupação de avaliação das políticas de saúde, bem como, para efetivar as estratégias de promoção da saúde, relacionando-as com as políticas públicas, observa-se uma lacuna no desenvolvimento de pesquisas, neste contexto, na perspectiva pós-estruturalista.

O desenvolver deste estudo nos permite inferir que as estratégias para a promoção da saúde, de caráter empoderador, são aquelas que envolvem diretamente a participação dos sujeitos nas decisões, destacando-se a forma como estes fazem suas escolhas, mostrando uma estreita relação entre o potencial de participação dos sujeitos e a distribuição de poder nesses espaços de promoção da saúde, quais sejam: teatro, círculo de cultura, terapia comunitária, oficina de escuta terapêutica, atividades lúdicas e workshop. Estas em consonância com as ações de promoção da saúde, apresentadas na Carta de Otawa. A visita domiciliar, a extensão universitária e os projetos de ação social também têm, por sua natureza, imponente caráter empoderador.

Contudo, as conjecturas iniciais do estudo se confirmam, os profissionais da saúde têm dificuldades de interpretar o real significado da aplicabilidade do empowerment no contexto das estratégias de promoção da saúde. Compreendese que toda estratégia de empowerment também o é de promoção da saúde, mas nem toda estratégia de promoção da saúde é empoderadora. Neste contexto, importa considerar o nível de envolvimento (consciente e intencional) do profissional de saúde em tais atividades, considerando suas habilidades com a comunidade, de modo a fomentar o desenvolvimento pessoal e social; sendo outro ponto importante a ser considerado, o apoio das organizações governamen- 
tais. Não há como pensar em processos de $\mathrm{em}$ powerment sem considerar o funcionamento da vida em sociedade, entre as quais, a intrapsíquica, a intersubjetiva e a étnico-cultural.

Quanto aos desenhos metodológicos das publicações analisadas, sugere-se maior rigor no que concerne às informações completas quanto ao problema de pesquisa, especificamente, ao método e suas etapas e à análise dos resultados, favorecendo a apreensão do leitor e contribuindo efetivamente para a prática profissional.

Sugere-se ainda, um aprofundamento nas discussões com os profissionais da saúde, especificamente os da Enfermagem, sobre a aplicabilidade do empowerment no contexto da promoção da saúde, envolvendo programas de formação permanente. Precisa-se explorar o conhecimento e a práxis destes profissionais tendo como

\section{Colaboradores}

JM Souza, FP Córdova e AD Tholl trabalharam na concepção teórica, elaboração, revisão bibliográfica e redação final do texto. ITSB Heidemann, AE Boehs e RG Nitschke participaram na revisão crítica e colaborações teóricas do artigo. fio condutor uma efetiva atribuição de significados aos resultados de pesquisas envolvendo tais estratégias para refletir e reconstruir sua prática profissional, sem deixar de considerar o indivíduo e a sua subjetividade em sociedade.

A presente revisão integrativa pode contribuir acerca de reflexões para mudanças de paradigmas no exercício profissional de saúde, no sentido de desmistificar as relações hierárquicas de poder entre este profissional e os grupos sociais, potencializando as características e suas ações no modo de viver. Ainda, sugere-se que as ações dos profissionais busquem estratégias que realmente sejam empoderadoras e direcionadas à promoção da saúde, não somente de cunho educativo. A construção de redes sociais de apoio e a mobilização de redes governamentais são essenciais neste processo.

\section{Referências}

1. Carvalho SR. Os múltiplos sentidos da categoria "empowerment" no projeto de promoção à saúde. Cad Saude Publica 2004; 24(4):1088-1095.

2. Carvalho, SR. Promoción de la Salud, "empowerment” y educación: una reflexión crítica como contribución a la reforma sanitária. Salud Colectiva 2008; 4(3):335-347.

3. World Health Organization (WHO). The ottawa charter for health promotion. Otawa: WHO; 1986.

4. Oliveira DL. A 'nova' saúde pública e a promoção da saúde via educação: entre a tradição e a inovação. R Latino-Am Enferm 2005; 13(3):423-431.

5. Wallerstein N. Powerlessness, empowerment and health: implications for health promotion programs. Am J Health Prom 1992; 6(3):197-205.

6. Streck DR, Redin E, Zitkoski J, organizadores. Dicionário Paulo Freire. Belo Horizonte: Autêntica Editora; 2008.

7. Freire P, Shor I. Medo de ousadia: o cotidiano do professor. Rio de Janeiro: Paz e Terra; 1986.

8. Cunha R. Educação libertadora como possibilidade de empowerment de pessoas estomizadas: desafio ao cuidado de enfermagem [tese]. Florianópolis: Universidade Federal de Santa Catarina; 2010.

9. Carvalho SR, Gastaldo D. Promoção à saúde e empoderamento: uma reflexão a partir das perspectivas crítico-social e pós-estruturalista. Cien Saude Colet 2008; 13(Supl. 2):2029-2040.

10. Peters M. (Posts-) modernism and structuralism: affinities and theoretical innovations. Sociol Research On-line 1999; 4(3):138-160.

11. Velloso ISC. Configurações das relações de poder no serviço de atendimento móvel de urgência de Belo Horizonte [tese]. Belo Horizonte: UFMG; 2011.

12. Freire P. Pedagogia da autonomia: saberes necessários à prática educativa. $25^{a}$ ed. São Paulo: Paz e Terra; 1996. 
13. Freire P. Pedagogia do oprimido. São Paulo: Paz e Terra; 2001.

14. Becker D, Edmundo K, Nunes NR, Bonatto D, Souza R. Empowerment e avaliação participativa em um programa de desenvolvimento local e promoção da saúde. Cien Saude Colet 2004; 9(3):655-667.

15. Ganog LH. Integrative reviews of nursing research. Res Nurs Health 1987; 10(1):1-11.

16. Mendes KDS, Silveira RCCP, Galvão CM. Revisão integrativa: método de pesquisa para a incorporação de evidências na saúde e na enfermagem. Texto Contexto Enferm 2008; 17(4):728-64.

17. Heidemann ITSB. A promoção da saúde e a concepção dialógica de Freire: possibilidades de sua inserção e limites no processo de trabalho das equipes de Saúde da Família [tese]. Ribeirão Preto: Universidade de São Paulo; 2006.

18. Foucault M. Microfísica do poder. $13^{\mathrm{a}}$ ed. Rio de Janeiro: Graal; 2011.

19. Meis C. Cultura e empowerment: promoção à saúde e prevenção da Aids entre prostitutas no Rio de Janeiro. Cien Saude Colet 2011; 16(Supl. 1):1437-444.

20. Harada MJCS, Pedroso GC, Pereira SR. O teatro como estratégias para a construção da paz. Acta Paul Enferm 2010; 23(3):429-32.

21. Mahmud AJ, Olander E, Wallenber L, Haglund BJ. Health promoting settings in primary healthy care: "halsotorg" an implementation analysis. BMC 2010; 10(707):1-9.

22. Leite SN, Tonolli LLM. Uma terceira via para a gente aprender as coisas femininas... perspectivas sobre o desenvolvimento de um projeto de promoção de saúde e cidadania de meninas. Interface (Botucatu) 2010; 14(35):933-942.

23. Queiroz SMPL, Moysés SJ, França BHS, Bisinelli JC, Moysés ST. Percursos para promoção da saúde bucal: a capacidade de líderes na Pastoral da crianca da Igreja Católica no Brasil. Interface (Botucatu) 2010; 14(34):619-632.

24. Edinburgh LD, Saewyc EM. A novel, intensive home visiting intervention for runaway, sexually exploited girls. J Spec Pediatr Nurs 2010; 21(1):1-12.

25. Monteiro EMLM, Vieira NFC. Educação em saúde a partir de Círculos de Cultura. Rev Bras Enferm 2010; 63(3):397-403.

26. Setti AFF, Bógus CM. Participação comunitária em um programa de intervenção em área de proteção ambiental. Saúde Soc 2010; 19(4):946-960.

27. Andrade FB, Ferreira Filha MO, Dias MD, Silva AO, Costa ICC, Lima ÉAR, Mendes CKTT. Promoção da saúde mental do idoso na atenção básica: as contribuições da Terapia Comunitária. Texto Contexto Enferm 2010; 19(1):129-136.

28. Schweigmann N, Rizzotti A, Castiglia G. Información, conocimiento y percepción sobre el riesgo de contraer el dengue en Argentina: dos experiencias de intervención para generar estrategias locales de control. Cad Saude Publica 2009; 25(Supl. 1):S137-S148.

29. Shurmann AT. Review of the Bangladesh Female Secondary School stipend Project using a social exclusion framework. J Health Popul Nutr 2009; 27(4):505-517.

30. Ferreira Filho MO, Dias MD, Andrade FB, Lima EAR, Ribeiro FF, Silva MSS. A terapia comunitária como estratégia de promoção de saúde mental: o caminho para o empoderamento. R Eletrôn Enferm 2009; 11(4):964-970
31. Grippo MVS, Fracolli LA. Avaliação de uma cartilha educativa de promoção ao cuidado da criança a partir da percepção da família sobre temas de saúde e cidadania. Rev Esc Enferm USP 2008; 42(3): 430-436.

32. Martínez-Maldonado M LL, Correa-Muñoz E, Mendoza-Núñez VM. Program of active aging in a rural Mexican community: a qualitative approach. BMC Public Health 2007; 7(276):1-9.

33. Oliveira SHS, Monteiro MAA, Lopes MSV. Strategies to Combat Poverty and their Interface with Health Promotion. R Latino-Am Enferm 2007; 15(Esp.):867873

34. Kleba ME, Comerlatto D, Colliselli L. Promoção do empoderamento com conselhos gestores de um pólo de educação permanente em saúde. Texto Contexto Enferm 2007; 16(2):335-342.

35. Zancan L, Adesse L. Informe sobre a Cooperação Brasil-Canadá em Promocão da Saúde. Cien Saude Colet 2004; 9(3):739-744.

36. Meneghel SN, Barbiani R, Steffen H, Wunder AP, Roza MD, Rotermund J, Brito S, Korndorfer C. Impacto de grupos de mulheres em situação de vulnerabilidade de gênero. Cad Saude Publica 2003. 19(4):955-963.

37. Masl CM, Suarez-Balcazar Y, Cassey MZ, Kinney L, Piotrowski H. Internet Access and Empowerment: a community-based health initiative. J Gen Intern Med 2003; 18(7):525-530.

38. Caponi S. Michel Foucault e a persistência do poder psiquiátrico. Cien Saude Colet 2009; 14(1):95-103.

39. Buss PM, Carvalho AI. Desenvolvimento da promoção da saúde no Brasil nos últimos vinte anos (1988-2008). Cien Saude Colet 2009; 14(6):2305-2316.

40. Vasconcelos E. Dispositivos associativos de luta e empoderamento de usuários, familiares e trabalhadores em saúde mental no Brasil. Vivência 2007; 32:173-206.

41. Beserra EP, Alves MDS, Pinheiro PNC, Vieira NFC. Educação ambiental e enfermagem: uma integração necessária. R Bras Enferm 2010; 63(5):848-852.

42. Lefévre F, Lefévre AMC, Madeira W. Hipertrofia das mediações, internet e empoderamento, no campo da saúde-doença. Saúde Soc 2007; 16(3):149-157.

43. Kleba ME, Wendhausen A. Empoderamento: processo de fortalecimento dos sujeitos nos espacos de participação social e democratização política. Saúde Soc 2009; 18(4):733-43.

44. Rumor PCF, Berns I, Heidemann ITSB, Mattos LHL, Wosny AM. A promoção da saúde nas práticas educativas da saúde da família. Cogitare Enferm 2010; 15(4):674-680.

45. Wendhausen ALP, Barbosa TM, Borba MC. Empoderamento e recursos para a participação em conselhos gestores. Saúde Soc 2006; 15(3):131-144.

46. Lefévre F, Lefévre AMC. Saúde, empoderamento e triangulação. Saúde Soc 2004; 13(2):32-38.

47. Ortega F. Biopolíticas da saúde: reflexões a partir de Michel Foucault, Agnes Heller e Hannah Arendt. Interface (Botucatu) 2004; 8(14):9-20

Artigo apresentado em 26/04/2013

Aprovado em 15/06/2013

Versão final apresentada em 25/06/2013 